\title{
Análisis iconográfico e iconológico de dos fotografías publicitarias de niños mapuches hechas por Araucanía
}

\section{Artículo de reflexión}

\section{Ángel Gutiérrez Jeria}

Universidad de La Frontera

angheleto@gmail.com

Magaly Ruiz-Mella

Universidad de La Frontera

magaly.ruiz@ufrontera.cl

Recibido: 30 de marzo de 2021

Aceptado: 11 de julio de 2021

Como citar este artículo: Gutiérrez Jeria, A. y Ruiz-Mella, M. (2022). Análisis iconográfico e iconológico de dos fotografías publicitarias de niños mapuches hechas por los capuchinos en la Araucanía. Calle14: revista de investigación en el campo del arte. 17(31), pp. 148-159. DOI: https://doi.org/10.14483/21450706.18696

\section{(a) (1)}

https://creativecommons.org/licenses/by/4.0/deed.es 


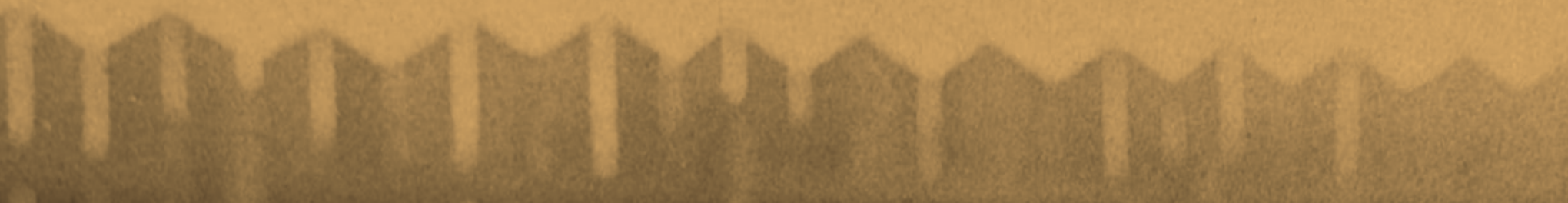 1.4 1}

$=$

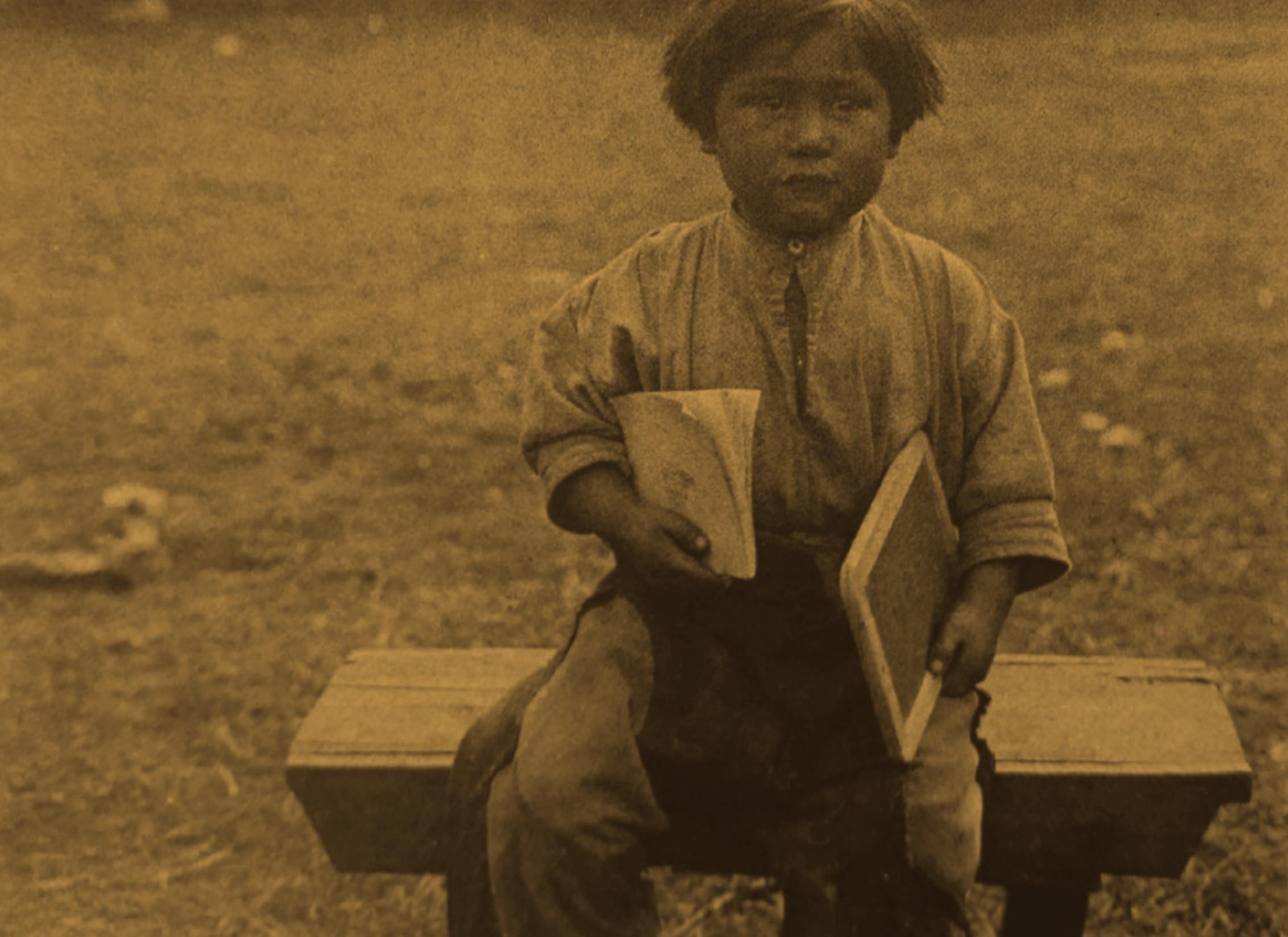


Análisis iconográfico e iconológico de dos fotografías publicitarias de niños mapuches hechas por los capuchinos en la Araucanía

\title{
Resumen
}

El registro fotográfico forma parte vital de nuestra cultura y nos permite informarnos y documentarnos de tiempos pasados. Asimismo, por medio del análisis formal e interpretativo de la imagen aprehendemos su significado y comprendemos la motivación y el contexto en el cual fueron hechas. En este artículo se analizan dos fotografías utilizadas como tarjetas publicitarias hechas por los capuchinos con el propósito de conseguir recursos económicos para seguir evangelizando la Araucanía. La metodología está basada en la propuesta de Panofsky (1979), actualizada en el trabajo de Lacruz (2010).

\section{Palabras clave}

Fotografía; iconografía; iconología; pueblo mapuche

Iconographic and iconological analysis of two publicity photographs of Mapuche children made by the Capuchins in Araucanía

\begin{abstract}
The photographic record is a vital part of our culture, and allows us to inform and document ourselves in times past. Likewise, through the formal and interpretive analysis of the image, we can seize its meaning and understand the motivation and the context in which it was made. This article analyzes two photographs used as advertising cards, made by the Capuchins with the purpose of obtaining financial resources to continue their evangelizing work in Araucanía. Our methodology is based on the proposal of Panofsky (1979) updated in the work of Lacruz (2010).
\end{abstract}

\section{Keywords}

Photography; iconography; iconology; Mapuche people

Analyse iconographique et iconologique de deux photographies publicitaires d'enfants mapuches réalisées par les capucins en Araucanie

\section{Résumé}

Le dossier photographique est un élément essentiel de notre culture, et nous permet de nous informer et de nous documenter dans le passé. De même, à travers l'analyse formelle et interprétative de l'image, nous pouvons saisir son sens et comprendre la motivation et le contexte dans lequel elle a été réalisée. Cet article analyse deux photographies utilisées comme cartes publicitaires et réalisées par les Capucins dans le but d'obtenir des ressources financières pour continuer à évangéliser l'Araucanie. La méthodologie est basée sur les propositions de Panofsky (1979) mise à jour dans les travaux de Lacruz (2010).

\section{Mots clés}

La photographie ; iconographique ; iconologique ; peuple mapuche

Análise iconográfica e iconológica de duas fotografias publicitárias de crianças mapuches feitas por capuchinos na Araucanía

\section{Resumo}

O registro fotográfico faz parte da nossa cultura vital e permite informar-nos e documentar-nos sobre tempo passados. Além do mais, por meio da análise formal e interpretativa da imagem aprendemos seu significado e compreendemos a motivação e o contexto no qual foram feitas. Neste artigo se analisa duas fotografias utilizadas como cartões publicitários feitos pelos Capuchinos com o propósito de conseguir recursos econômicos para seguir evangelizando a 
Araucanía. A metodologia está baseada na proposta de Panofsky (1979) atualizada no trabalho de Lacruz (2010).

\section{Palavras chave}

Fotografia; iconográfico; iconológico; povo mapuche

Kauaikunata katichii iachaikungapa kai iskai fotokuna churaskakuna wambrakunata mapuches sutimanda kai kapuchinukuna ruraska Araurcanía sutipi

\section{Maillallachiska:}

Kai ruraskata fotopi churaska kaimi mailla Nukanchipa kausaskata kawachingapa chasa mana Tukui chingaringapa ñugpamanda kausaita. Chasallata kaillawantata mana sakisunchi tukurichu kunaura samunakuskata parlangapa ima pasarii tiaskata. Samunakuskata parlangapa ima pasarii tiaskata. Kui kilkaipi churanaku iskai fotokuna uchulla pangapi ruraska capuchinos suti chasa ruranakuska kulki maskangapa kai Araucanía. Sutipi evangelizangapa, kai kilkai maki ruraska Panofsky suti runa 1979 chasallata ruraska de la cruz 2020 watapi.

\section{Rimangapa Ministidukuna:}

Ruraska; ñugpamanda kunata ruradur; kawachiikuna ñugapanda; Nukanchipa alpamanda 


\section{La fotografía como técnica de registro etnográfico}

La fotografía ha evolucionado desde su invención a finales del siglo XIX. Pasando desde los daguerrotipos al papel fotográfico y posteriormente al negativo, y con la aparición de cámaras fotográficas de fácil uso al ser portátiles, los fotógrafos pueden retratar la realidad en diversos contextos que la convierte en un instrumento que registra con facilidad diferentes temáticas sociales.

Este tipo de fotografía nos permite captar imágenes de individuos inmersos en su cultura, su contexto cotidiano, su entorno social y geográfico al que pertenecen, como son influenciados en la convivencia y relación con dicho medio. Por esta razón antropología y fotografía en la mayoría de los casos se complementan, siendo la fotografía una herramienta de trabajo más ágil y rápida de registro. Mientras la antropología estudia al ser humano en toda su dimensionalidad, la fotografía participa en este trabajo al registrar las imágenes para transformarse en documentos de estudios y archivos de análisis posterior. Por lo tanto, las imágenes fotográficas desde la visión antropológica ofrecen un vasto campo semántico de conocimiento más profundo de nuestras culturas y en la visualización del otro (Brisset, 1999).

Este género de comunicación visual, utilizado como documento histórico, registra un acontecimiento que se desarrolla dentro de un espacio y un tiempo específico e irrepetible, lo que permite que la fotografía se convierta en una excelente herramienta para el trabajo documental y la creación de memoria. Si el antropólogo decide apoyarse en este recurso necesita desarrollar y dominar las capacidades y destrezas técnicas del manejo de la cámara y los aspectos composicionales de una fotografía. Entre ellos, el encuadre, ángulos de visión, centro de interés, luminosidad, entre otros. Por lo tanto, la etnofotografía es una disciplina que se propone definir, precisar y aplicar las reglas más rigurosas al uso de la fotografía en las ciencias humanas." (Garrigues, 2009). En este sentido, la etnofotografía se convierte en una herramienta de comprensión de diferentes grupos humanos y culturas antiguas como actuales al aprehender el significado cultural que tienen los sujetos $y$ objetos fotografiados. Ya en el siglo XVIII existe interés de antropólogos y naturalistas en estudiar las culturas indígenas de América. Se interesan en el estudio de la supervivencia de los diferentes pueblos originarios, su adaptación y convivencia con el entorno y medio geográfico. De esta forma y por este medio es posible captar el contexto global del paisaje y sus habitantes.

\section{Antecedente de la etnofotografía en Chile}

En este apartado se destaca brevemente la obra precursora de los naturalistas europeos Mauricio Rugendas y Claudio Gay como exponentes importantes de la cultura y costumbres de nuestro país. El trabajo de ambos especialistas ha sido utilizado como antecedente etnográfico desde principios del siglo XIX. Mauricio Rugendas, pintor bávaro, exponente del romanticismo europeo, quien a través de su trabajo pictográfico representa el paisaje, los personajes populares de la época, y en especial el mundo indígena de la región de la Araucanía. Esto lo convierte a él y a su obra en un colaborador "en la construcción de una imagen de carácter paradigmático que fue útil para representar al indígena de las primeras décadas del siglo XIX." (Gallardo, 2012). A modo de ejemplo, el carácter etnográfico de este pintor se observa en las figuras frontales que lucen sus atuendos y accesorios decorativos mapuches en las imágenes 1 y 2 .

En cuanto a Claudio Gay, ciéntifico, historiador y dibujante autodidacta francés, es contratado por el gobierno chileno para estudiar la flora y fauna y geografía del Chile de antaño. A pesar de que su trabajo en nuestro país tiene un propósito científico, a través de sus grabados, capta imágenes de indígenas y personajes populares hasta ese entonces desconocidas. Entre su prolífera obra, destacamos el manuscrito Usos y costumbre de los Araucanos en el que registra etnográficamente las costumbres típicas de un pueblo. Asimismo, es posible vislumbrar en esta obra "de manera marginal pero muy flagrante, los hechos que marcarían el futuro del pueblo mapuche con alto nivel de precisión, y se percata muy bien de que el corazón de los conflictos de la última década se encuentra en la adquisición informal, confusa y fraudulenta de tierras que eran de su propiedad." (Cabello, 2018).

\section{Registro fotográfico de los Capuchinos en La Araucanía}

En el año 1895 misionan en la Araucanía la Orden de los Capuchinos bávaros. Estos sacerdotes traen consigo la cámara fotográfica que les permite graficar sus actividades misioneras y evangelizadoras con este instrumento. Este registro visual se convierte en un medio para publicitar su obra religiosa y así conseguir los fondos económico 


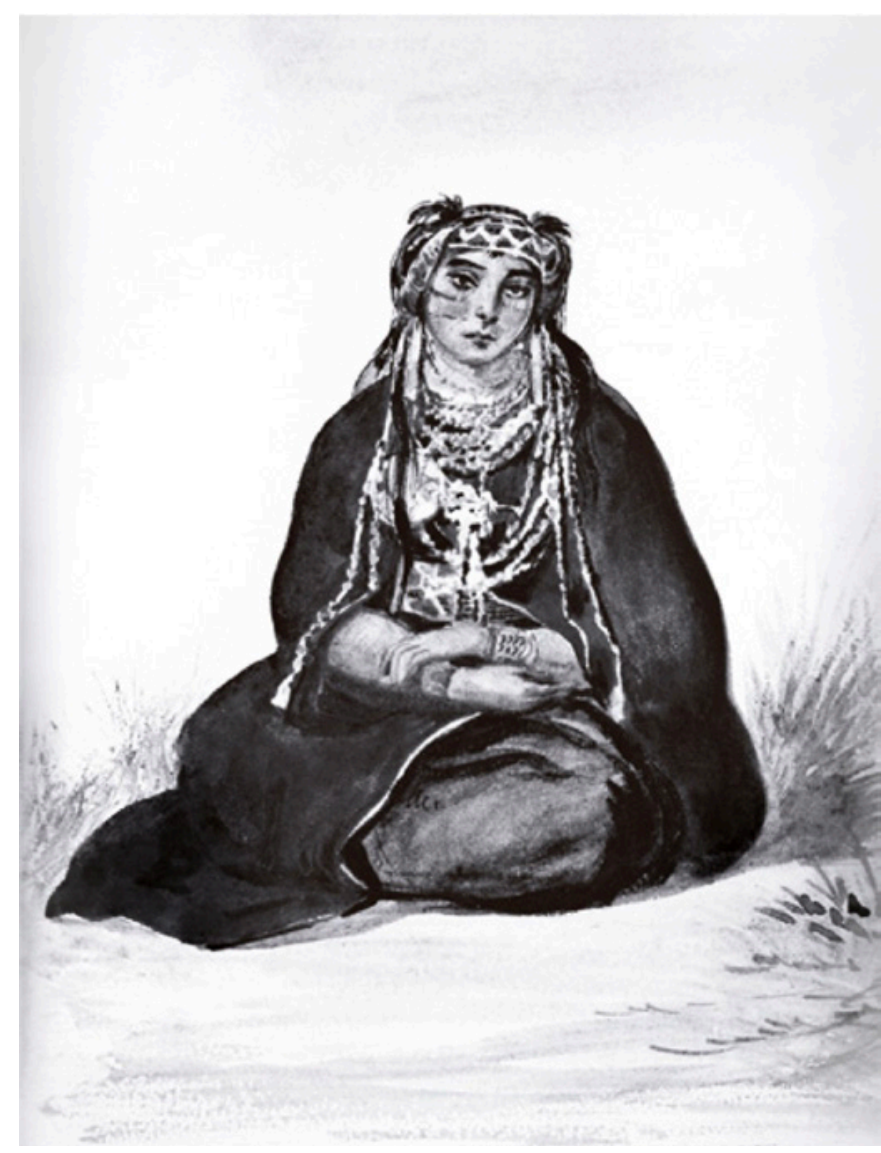

Imagen 1. Mujer araucana. Pinturas de Mario Rugendas. Fuente: Archivo Fotografico y Digital. Biblioteca Nacional de Chile.
Imagen 2. Cacique pehuenche. Pinturas de Mario Rugendas. Fuente: Archivo Fotografico y Digital. Biblioteca Nacional de Chile.

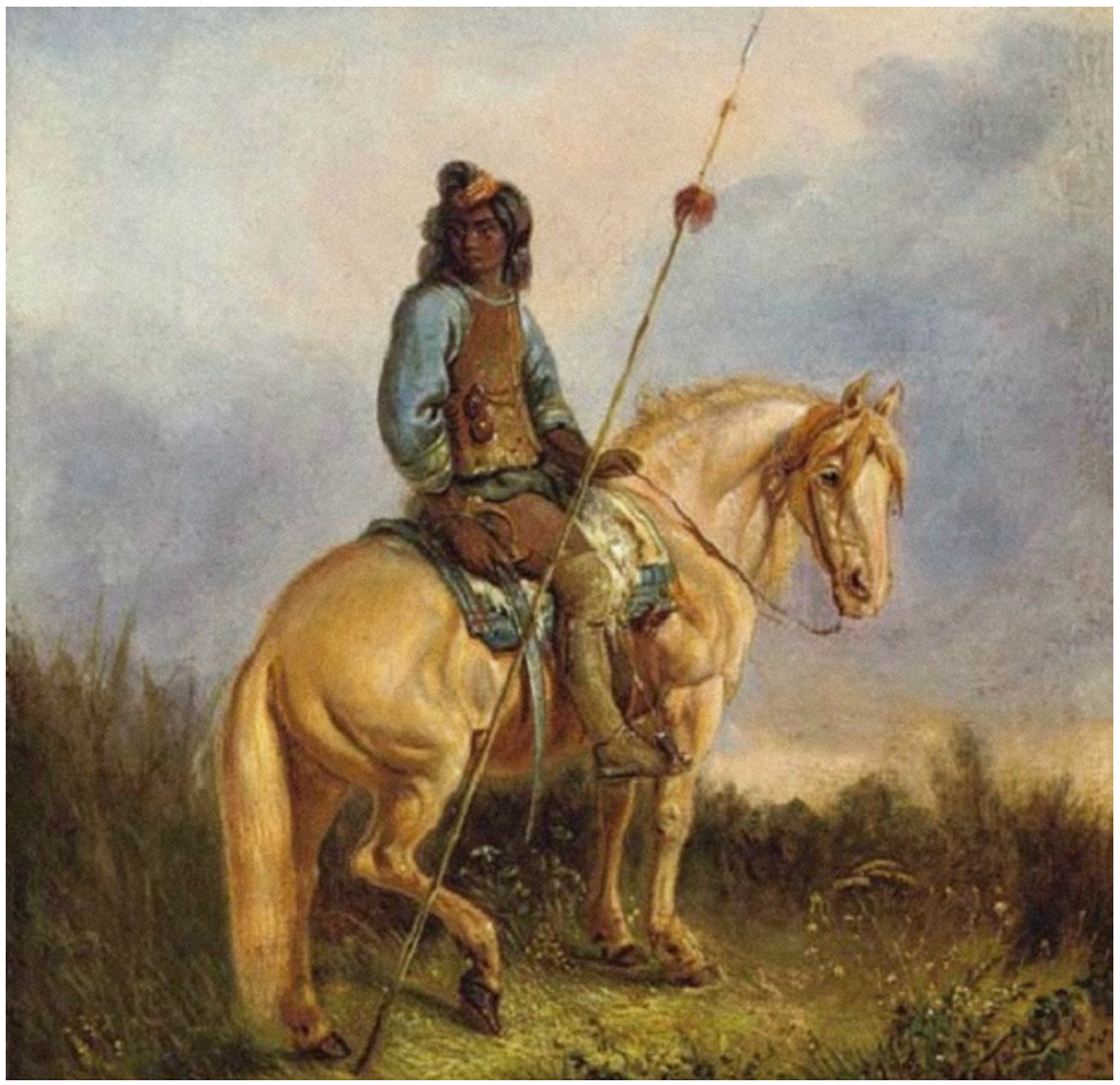


necesarios para continuar con su labor en el territorio araucano. Asimismo, esta intervención capuchina influye con fuerza en la construcción de la imagen del mapuche en una época determinada de la historia.

Este recurso tecnológico explicita la disyuntiva entre la modernidad y la realidad "prehistórica" de los pueblos originarios. A través de la fotografía, los frailes visualizan al indígena salvaje como un ser necesario de civilizar. De esta forma, a través del lenguaje no verbal, se construye la identidad del habitante de la Araucanía vista desde un prisma cultural hegemónico de occidente. Con los recursos y avances científicos en contraste con la barbarie, es posible observar en las fotografías al religioso misionero, representante del hombre moderno en contraste con el indígena bárbaro, salvaje y pagano. Al civilizador y educador con el poder de transformar al mapuche, civilizarlo y evangelizarlo despojándolo de sus prácticas sociales, paganas y culturales.

Este tipo de fotografía elaborada por los Capuchinos y otras similares hechas por fotógrafos independientes comenzaron a circular por Chile y Europa. En periódicos, libros y diseño de postales se muestra un discurso socio-semántico de la realidad de la Araucanía, manipulando los elementos presentes en las fotografías. El mensaje predominante de estos elementos gráficos distorsiona la realidad existente del pueblo de la Araucanía con el propósito de "Evangelizar, civilizar y chilenizar a los mapuches" (Flores y Azócar, 2015).

\section{Dos fotografías para el análisis}

En este apartado se analizan dos fotografías de los misioneros Capuchinos asentados en la Araucanía. Ambas instantáneas son tomadas del texto de Flores y Azócar 2015:161-162. Por una parte, de describe la intencionalidad del emisor (los Capuchinos) y por otro el receptor del mensaje expuesto en las fotografías (europeos y chilenos con recursos económicos para invertir).

La metodología utilizada en el análisis de ambas fotografías es de orden cualitativa dividida en dos fases: una es iconográfica y la otra iconológica, de acuerdo a los propuesto por Panofsky (1979) y actualizado

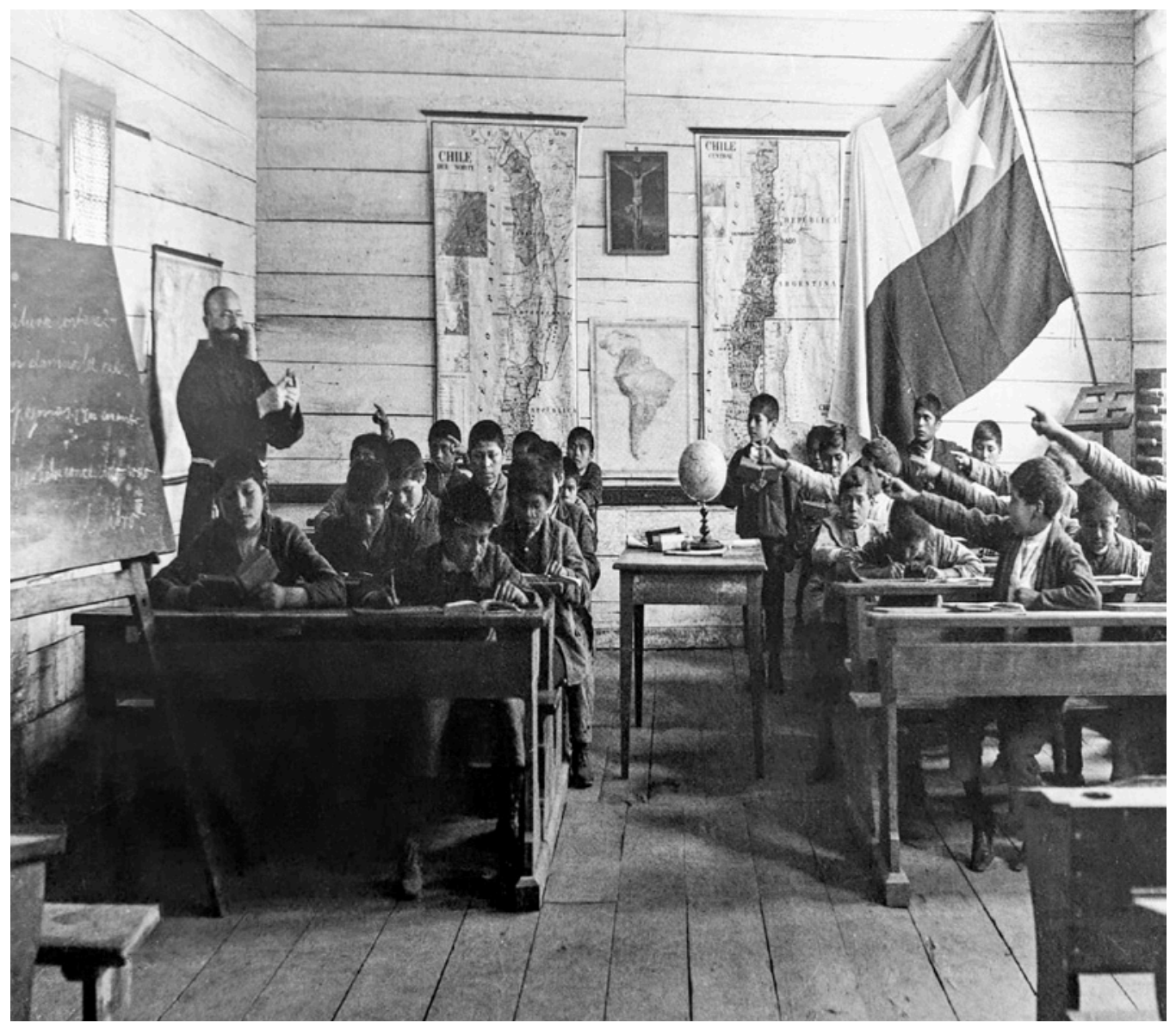

Imagen 3. Aula de una escuela misional. 
por Lacruz, 2010. En la primera de ellas, se hace una descripción formal de cada foto. Se responde a la pregunta de cómo fueron construidas y percibidas en su momento. En la segunda parte se realiza un análisis, que pretende dar cuenta de cómo ambas fotografías funcionan como artefactos icónicos socialmente significativos en el contexto histórico en que se realizaron, y qué significados implícitos relevantes están presentes para el espectador actual (Brisset 1999: 8).

\section{Análisis de la fotografía "Aula de una escuela misional"}

\section{Análisis Iconográfico de la Imagen 3}

La imagen 3 corresponde a la fotografía que se encuentra en la antigua Biblioteca Central de los Capuchinos bávaros en Altotting, Alemania. El código de búsqueda es VA15_S60_010, Caja 60. Lleva por título “El padre Franz en el interior de una escuela misional" probablemente en Pelchuquín. El género a la que pertenece es Fotografía tipo postal.

El contexto geográfico al que pertenece el episodio registrado corresponde a una escuela ubicada probablemente en una localidad cercana a San José de Mariquina, actualmente Región de Los Lagos. La temática de la imagen es mostrar el trabajo modernizador de la orden religiosa, acorde con los deseos del estado chileno para educar para el trabajo. Además del padre Franz, se encuentran otros participantes, que corresponden a niños mapuches vestidos con ropas occidentales. Este tipo de foto-tarjeta permite a los frailes recolectar dinero para continuar con la tarea de evangelizar y chilenizar la zona sur de país (Flores y Azócar, 2015:65).

El espacio físico de la fotografía es la sala de clases de madera en una típica escuela misional. La toma de la instantánea es frontal, en que se visualiza a primera vista elementos de madera; entre ellos, los pupitres de estudio bipersonales sin respaldo y el pizarrón del maestro. En la sala están presentes 25 niños con características étnicas mapuches entre los 10 a 12 años de edad, distribuidos en dos grupos: 13 niños en el sector izquierdo y 12 niños en el sector derecho.

El recorrido visual de la imagen es posible leerlo de izquierda a derecha y de arriba hacia abajo, terminando en el centro de la foto, simulando un recorrido en espiral. En el espacio izquierdo se encuentra el padre Franz, y a su espalda se observa una ilustración posiblemente de carácter religioso, una pequeña ventana rectangular con cortinas y una pizarra con alguna materia escrita. En la pared del fondo de la sala se encuentran cinco elementos distribuidos casi simétricamente. En el sector izquierdo se ubica la parte norte del mapa de Chile y en el sector derecho de la pared la parte sur del país. En la parte central alta una iconografía de Cristo crucificado, y en la parte baja el mapa de América, terminando en el centro de la sala una mesa con el mapamundi y algunos libros. Por último, en el sector derecho, una ventana abierta que ilumina ese sector, con una bandera chilena apoyada en un trípode musical, un ábaco y, finalmente terminando el recorrido visual con un niño de pie sosteniendo un libro abierto.

\section{Análisis Iconológico de la Imagen 3}

El análisis se ordena de acuerdo a los parámetros propuestos por Arnheim (2002): elementos compositivos, distribución del formato y centro óptico de líneas de fuerza e interés.

La fotografía realizada por los Capuchinos no cuenta con una composición artística de calidad. Está fraccionada de forma vertical, partiendo la fotografía en dos grupos, teniendo mayor peso visual el sector izquierdo de la composición, en desmedro del espacio derecho. Asimismo, carece de un recorrido visual, sin centro de interés, y con una distribución de los elementos casi simétrica. De todos modos, no era la intención de los Capuchino realizar fotografías artísticas, sino más bien producir fotografías con el propósito de publicitar sus actividades misioneras y evangelizadoras. Es por ello que en la fotografía es evidente la manipulación de la ubicación de los elementos en el espacio fotográfico.

Con el claro propósito propagandístico, se evidencian en la imagen dos grupos de alumnos, cada uno con características propias. Uno de ellos, ubicado a la derecha de la foto, se observan niños muy activos, levantando su dedo con la clara intención de responder a las preguntas del sacerdote. Este acto de reacción positiva puede ser percibido por el observador como una acción civilizadora de participación activa de estos niños a las preguntas del padre Franz. No es casual que este grupo esté inmerso en la luz que entra por la ventana. Es una forma de indicar que los niños mapuches han sido envueltos en el conocimiento de la cultura civilizadora de occidente. Además, este grupo "civilizado" está amparado a la sombra de la bandera chilena, haciendo alusión de cómo el estado chileno junto a la iglesia es capaz de eliminar la "barbarie" inherente a los pueblos indígenas (Azócar et al, 2015:218). El grupo de la derecha apuntan sus dedos hacia el padre Franz que se encuentra ubicado 
en el grupo de alumnos no activos de la izquierda. Este sector se encuentra en mayor penumbra, indicando que se encuentra en proceso de civilización, gracias a la intervención religiosa del padre Capuchino.

La obra no cuenta con un centro de interés particular; sin embargo, se advierte una serie de elementos visuales, con una alta carga semántica, que busca entregar un mensaje propagandístico. Uno de ellos es la figura del padre Franz, que no por casualidad se ubica de pie en el sector izquierdo donde están sentados los niños mapuches en vías de evangelizar y chilenizar. Es posible leer en la fotografía que la tarea misionera de los Capuchinos todavía está en proceso; esto se evidencia al observar en el fondo en el lado izquierdo de la imagen como un niño mapuche tímidamente levanta su mano indicando que se vislumbra en él el efecto de la civilización.

Otro elemento visual destacable es el niño de pie junto a la mesa ubicado más a la derecha de la foto. Está con un libro abierto, posiblemente la Biblia, quizá preparándose para realizar la catequesis en la que se reciben las instrucciones de la vida católica. Este niño es claro símbolo de aquel alumno destacado que puede leer con mayor fluidez, dando clara cuenta de la acción evangelizadora de la Iglesia Católica.

Por último, si nos referimos al centro óptico de líneas de fuerza e interés en la fotografía, sin duda es el padre Franz el que ocupa un lugar privilegiado dentro de la imagen. Este recorrido continúa con los primeros alumnos del sector izquierdo, que se contraponen con los estudiantes del lado derecho de la foto, guiándonos visualmente hacia la diagonal de la imagen en la que culmina con una gran bandera chilena. Este símbolo patrio ocupa un gran espacio dentro de la imagen que no deja duda la intención de chilenizar al pueblo mapuche, especialmente comenzando con los más pequeños de este pueblo. Por lo tanto, en esencia esta fotografía expone en su discurso visual el papel evangelizador de la iglesia católica por medio de la obra Capuchina, que unida al poder del Estado chileno son capaces de civilizar a un pueblo que se encuentra sumido en la barbarie.

\section{Análisis de la fotografía: "Niño mapuche con cuaderno y pizarra"}

\section{Análisis Iconográfico de la Imagen 4}

El título de la fotografía (imagen 4) "Niño mapuche con cuaderno y pizarra". Como la fotografía anterior (Imagen
3) también se encuentra en la Antigua Biblioteca Central de los Capuchinos bávaros en Altotting, Alemania. Clasificación: VA15_S55_007 Box 55. Fotografía blanco y negro. Género: Fotografía tipo postal.

La fotografía tiene como elemento principal a un niño de 8 a 10 años con características físicas de la etnia mapuche. Está sentado en una banca en una posición frontal al espectador, vestido con una camisa blanca abotonada en el cuello semi desabrochada a la altura del pecho. Las mangas de la camisa son tres cuartos: sobrepasan el codo, pero no llegan a la muñeca. Viste un pantalón elaborado con retazos de géneros, lo que indica la modestia de la vestimenta del niño. Sostiene en su mano derecha un cuaderno y en su mano izquierda una pizarra. La fotografía está ambientada en un patio exterior trasero de una vivienda presentando una cerca de madera en el fondo.

\section{Análisis Iconológico de la Imagen 4}

Esta fotografía corresponde a una imagen conmovedora de un niño mapuche de corta edad. Está sentado en un banco occidental y no en un wanco, banco tradicional mapuche realizado en una sola pieza de madera de raulí, piramidal en su base y ovalada en la superficie. Su vestimenta es ajena a su cultura y, por lo que observamos en la fotografía, no corresponde a su talla. Le queda estrecha a nivel del cuello y pecho y corto de mangas. Sus pantalones anchos y arrugados reflejan el poco cuidado de vestirlo apropiadamente para una fotografía que tiene como propósito dar valor a la alfabetización en las misiones de los Capuchinos en la Araucanía. Los sacerdotes lo han desprovisto de su vestimenta tradicional por considerarla inapropiada para este evento.

Asimismo, el niño carga con dos elementos ajenos a su cultura educativa: una pizarra en su brazo izquierdo y un libro o cuaderno en su mano derecha. Sin embargo, el aspecto más dramático se encuentra en el corte de pelo del protagonista. Similar a lo observado en la fotografía de la imagen 3 , donde todos los niños presentan un corte de pelo muy a la nuca, en la imagen 4 este niño también tiene cortado su pelo a la usanza occidental, pero no tan extremo. No obstante, queda claro que una de las señales que indican la civilización y chilenización de estos niños mapuches es su corte de pelo. ${ }^{1}$

Pero qué significado tiene el pelo largo en los hombres pertenecientes a los pueblos originarios. El cabello en

1 Relato proporcionado por Antonio Chihuaicura Chihuaicura, kimeltuchefe de la comunidad de Chol-Chol. 


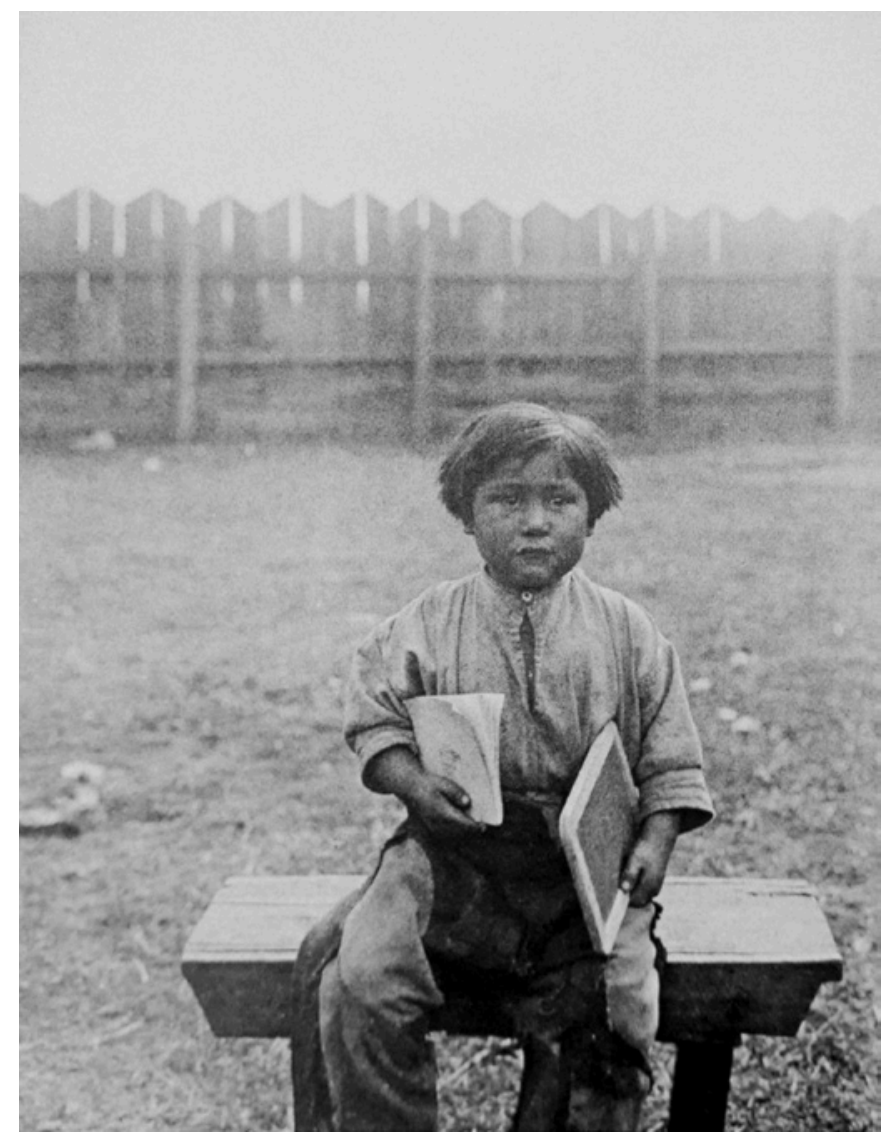

los pueblos indígenas representa la extensión de los pensamientos, la proyección de sí mismo. A través del pelo largo es posible conexión con la madre tierra, la que a su vez nutre de energía y fuerza natural el espacio donde se habita. En este espacio conviven en armonía la lluvia, el viento, los animales, y todo lo creado (Klug, P., 2013). Por lo tanto, el pelo en la cosmovisión mapuche (como también en otras cosmogonías indígenas) simboliza la vida. Es por ello que son muy cuidadosos con el cabello. Deben cortarlo en luna nueva hasta la altura de los hombros, posteriormente debe ser enterrado en un lugar secreto de forma ceremonial evitando que tenga contacto con el agua.

La puesta en escena en la fotografía es de un espacio cerrado por un cerco de madera tradicional, con tablones anchos y tupidos, terminados en punta, y de una altura lo suficientemente alto para que no se pueda ver a través ni encima de él. Esta tapia se encuentra a las espaldas del niño, lo que indica que es imposible volver a sus orígenes. Todo lo aprendido a su corta edad es rechazado y debe ser puesto en el olvido. No tiene escapatoria, porque frente a él se ubica el fraile con un objeto extraño que es la cámara fotográfica. En esta puesta en escena el Capuchino dirige al niño mapuche en sus movimientos y postura. Ha comenzado
Imagen 4. Niño mapuche con cuaderno y pizarra.

el proceso de civilización deseado por los misioneros y por la sociedad chilena.

En suma, en esta fotografía se expone a un niño mapuche sentado frontalmente al espectador como un objeto en exhibición. Se encuentra desprovisto de los elementos que le dan identidad: su cabello y sus ropas, y se le "reviste" con indumentaria ajena, un cuaderno y una pizarra carente de significado para él. Su rostro refleja el desconcierto e infelicidad, que recuerdan a las figuras del pintor Francés Jean A. Watteau, en especial la obra del Pierrot.

\section{Discusión y Conclusiones}

Por medio del análisis de dos fotografías-tarjetas publicitarias realizadas por la Orden de los Capuchinos en la Araucanía, podemos observar la narración de una historia dolorosa de despojo de identidad en los pueblos originarios por medio de la acción de religiosos aliados con el estado chileno para evangelizar, civilizar y chilenizar los niños mapuches de la Araucanía. Estas fotografías por ser retratos de niños de corta edad son mucho más impactantes, y pone de manifiesto lo cuestionable del proceso de civilización en la zona sur del país. En la 
primera foto analizada los niños solo tienen una meta: pertenecer a la patria con obediencia a las reglas de la misma. Homogeneizar es la consigna, y todos aquellos que no abrazan con calor y alegría este principio, quedarán sumidos en la oscuridad e ignorancia, como puede verse en el grupo de alumnos que no participa de la clase y que la luz de la ventana no les llega.

Este mismo principio se cumple de forma mucho más patente, en la segunda fotografía analizada en este trabajo: la de un niño mapuche solo frente a su destino. La historia transmitida es la de una figura infantil con expresión de melancolía y desconcierto en una postura rígida. Este niño mapuche solitario e incomprendido, se le ha desprovisto de su entorno social y cultural. Se le ha vedado la oportunidad de seguir perteneciendo e identificarse con su propio pueblo. En cambio, se le insertado una cultura y sociedad que no comprende; los objetos en sus brazos se ven ajenos a él. El propósito de su vida ya no es el de sus antepasados, por ello en la fotografía la imagen del niño se encuentra en un espacio cercado, sin escapatoria.

En este análisis iconológico e iconográfico de ambas fotografías publicitarias es patente el juego dicotómico entre civilización y barbarie. No solo observado en nuestro país, sino también sufrido en otras culturas originarias (de la Barra, 2000). Los elementos visuales como la luz, que simboliza conocimiento y sabiduría occidental, se contraponen con la oscuridad, que representa a un pueblo sumido en la ignorancia. Los objetos presentes en ambas fotografías representan el conocimiento y sabiduría, desmarcándose de lo instintivo y oscuro, elementos que no están presentes en ambas imágenes, pues los niños ni siquiera pueden lucir una larga cabellera para no ser vistos como salvajes. No olvidemos que estas fotografías están hechas con el propósito de conseguir más dinero para el proceso de evangelización, civilización y chilenización del pueblo mapuche. Por lo tanto, ambas fotografías son un valioso documento que nos hablan hasta ahora de como en todo proceso de homogeneización de los pueblos originarios, son los niños y niñas los que sufren las mayores pérdidas: el despojo de la cultura y la negación de los valores ancestrales; es decir, la pérdida de identidad.
Avendaño, A., Chávez, J. F., \& Dietz, S. L. 2015. “La tarjeta postal fotográfica y la escuela misional en la Araucanía". Signa: Revista de la Asociación Española de Semiótica, (24), 215-230.

Brisset, D. 1999. "Acerca de la fotografía etnográfica.". Gazeta de Antropología. 15:1-13.

Cabello, J.B. 2018. “Claudio Gay. Usos y Costumbres de los Araucanos (Traducido y editado por Diego Milos)". Antropologías del Sur. 5(10): 201-204.

De la Barra, L. 2000. “La Pareja Conceptual Civilización-Barbarie: Norte y Sudamérica. La Novela Indigenista de Lautaro Yankas". Disponible en:https:// revistaestudiostributarios.uchile.cl/index.php/RCH/ article/view/9092 (consultado en marzo de 2021)

Flores, J., \& Azócar, A. 2015. Evangelizar, civilizar y chilenizar a los mapuche. Fotografías de la acción de los misioneros capuchinos en La Araucanía. Temuco: Ediciones Universidad de La Frontera, Editorial Universidad de Sevilla.

Gallardo, V. 2012. "Rugendas, artista viajero y su aporte a la construcción de la representación indígena". Tiempo Histórico. 4:67-86.

Garrigues, E. 2009. “¿Qué es la etnofotografía?: Introducción a la entrevista con Pierre Verger." Revista valenciana d'etnologia. 4: 17-36.

Klug, P. 2013. "La importancia del cabello largo en las culturas indígenas americanas." Disponible en: https://tinyurl.com/2t3zm6en (consultado en marzo de 2021)

Lacruz, M.D.C. 2010. “El contenido de las imágenes y su análisis en entornos documentales". Polisemias visuales. Aproximaciones a la alfabetización visual en la sociedad intercultural. Gómez-Díaz, R., \& Agustín Lacruz, M. D. C. (Eds.). Salamanca: Universidad de Salamanca ediciones.85-116.

Panofsky, E. 1979. El significado de las artes visuales. Madrid, Alianza.

\section{Referencias}

Arnheim, R. 2002. Arte y percepción visual: psicología del ojo creador. Madrid: Alianza editorial. 